\title{
X. Internationaler medizinischer Kongress in Budapest
}

vom 29. August bis 4. September 1909

In der Sektion für Augenlieilkunde werden folgende Referate und Vorträge gehalten werden: Referate.

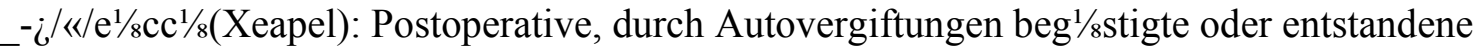
Augenentzündungen.

Elschnig (Prag): Infektionsverhütung bei Bulbusoperationen.

Goldzieher (Budapest): Pathologie des ïrachoms.

Breeff (Berlin): Zur Aetiologie des Trachoms.

Hess (Würzburg): Ueber Star- und Nachstar-Operationen.

Hirschberg (Berlin): Prophylaxe des Trachoms.

Jessop (London): The serum treatment of diseases of the eye.

Kuhnt (Bonn): Operative Behandlung des Strabismus concomitans.

Lagrange (Bordeaux): Traitement du glaucome chronique.

Lapersonne (Paris): Du role des infections, particulièrement de la syphilis, dans la production des lesions de la myopie progressive.

Leber (Berlin): Serodiagnostik der Augenerkrankungen.

Morax (Paris): Etiologie des infections post-opératoires subaiguës et tardives.

Römer (Greifswald): Serumtherapie in der Augenheilkunde.

Sulzer (Paris): La prophylaxie du trachome.

True (Montpellier): L'iridectomie et la sclérotomie.

Uhthoff (Breslau): Augensymptome bei den Hypophysisaffektionen und der Akromegalie.

Weeks (New-York): Serum and vaccine therapy in ophtalmok $>$ gy.

Vorträge:

AntoneUi (Paris): Pathologie naso-lacrymale dans Thérédosyphüis.- Axenfeld (Freiburg i. B.): Blutdruck und intraoculare Tension bei Glau-kom. - Erdridge-Green (London): Some curious phenomena of vision and colour vision. - Eversbusch (Miinchen): Thema vorbehalten. - Falta (Szeged): Beitrag zur Trachomtherapie (Instrumentendemonstration). 570

Tagesnotizen.

Fejér (Budapest): Beiträge zmn Krankheitsverla·ufe und zur Behandlung der Embolie der Zentralarterie der Netzhaut. - Fukala (Wien): 1. Was ist zu tun, wenn bei Glaucoma nach der Operation sich die Kammer nicht herstellt ? 2. Wie soil man den Augapfel bei Star- und Glaukomoperationen vollkommen unempfindlich machen ? - Genersich (Hódmezövásárhely): Le collargol contre les suppurations cornéennes. - Imre (Hódmezövásárhely): Neue Operation gegen das Entropium spastieum habituale. -Márquez, M. (Madrid): Sur un nouveau procédé opératoire du distichiasis. -- Márquez. T. A. (Madrid): Du chlorhydrate de codeine dans la thérapeutique ocu-laire. - Nedden (Essen a. d. R.): Die Bedeutung der Autocytotoxine fur die Entstehung von Augenkrankheiten. - - Oliver (Philadelphia): Transferred ophtalmitis. - Onodi (Budapest): Das Verhältnis der Nasennebenhöhlen zum Sehnerv und zu den Augennerven. 
Paunz (Budapest): Beiträge zur Mukokele fronto-ethmoidalis. - Posselc (Graz): Zur Aetiologie der Linsentrübungen. - Schmidt-Rimpler (Halle): Bemerkungen zur Glaukom-Therapie. Siklóssy (Budapest): 1. Ueber die Bedingungen der körper-lichen Tauglichkeit der Eisenhahnangestellten mit Rücksícht auf das Seh-organ bei deren Aufnahme und bei periodischen Prüfungen. 2. Ueber die Messeinheit der Sehschärfebestimmung. - Vajda (Miskolcz): Die Bedeutung der Weitsichtigkeit bei den Fabriksarbeitern und Gewerbsmännern. Vossius (Giessen): Gesichtsasymmetrien und Strabismus. - Wicherkiewicz (Krakau): 1. Meine Erfahrungen über die Kammerausspülungen bei Star-operationen. 2. Sur Гopération des cataractes non-mûres. 3. Ueber spon-tane Irisatrophie. 4. Einiges über Anophthalmus congenitus und kon-genitale Lidcysten.

Tagesnotizen.

Geheimrat v. Zehender in Rostock beging $\xi$ in vollster geistiger und körperlicher Frische am 21 . Mai semen 90. Geburtstag. Wir gestatten uns, dem hochverdienten und hochverehrten Senior der deutschen Ophthalmologen unsere herzlichsten Glückwünsche auszusprechen.

Zum ordentlichen Professor der Augenheilkunde an der Universität Klausenberg, SiebenbürgenUngarn, wurde zum Ersatze von Professor Hoor, der die zweite Augenklinik in Budapest

übernimmt, der Chefarzt des ophthalmologischen Spitals in Hodmezö-Vasarhely, Dr. Josef Imre, berufen.

Am 20. April starb der Direktor der Universitäts-Augenklinik in Dorpat (Jurjew), Professor Th. v. Ewetzky.

Dr. Koellner und Dr. Leber, Assistenten der Universitäts-Augenklinik in Berlin, und Dr. Löhlein in Greifswald, haben sich habilitiert.

U. Um Eínsßndung von Separatabdrücken wird gebeten.

Vßrantwortlicher R $\beta$ dakt $\beta U \Gamma$ : Prof. Kuhnt in Bonn a. Rh. 